The compounds, which are difficult to dissolve in water but more or less soluble in different fat solvents, possess lipophilic qualities in the wide sense of the term. They have been tested in vitro-in some cases in vivo also, due to the difficulty of dissolving them. in water-against pneumococei of types I and III and against $E$. coli and have been compared with sulphanilamide and other compounds. All the compounds showed activity, particularly 1, which has a growth-inhibiting effect of the same magnitude as that of sulphapyridine. Experiments have been instituted to discover whether compounds of this type have any action on the tubercle bacillus. The synthesis of other similar compounds is also being attempted.

Since certain vital dyes have an affinity for $M y c o b$. tuberculosis, we have started making substitutions in different sulphanilamides with groups which ean be regarded as characteristic of the compounds showing this affinity. The substitution must, however, be done in such a way that the sulphanilamide derivatives fulfil the fundamental conditions for a chemotherapeutic effect. This should be feasible, since these conditions are now rather well understood. If it were possible at the same time-due to the substitution-to obtain an affinity, this might conceivably lead to a better contact. We intend to investigate this question.

Central Laboratories,

Bertil SJöGREN.

Astra, Södertälje.

Sept. 2.

${ }^{1}$ Cf. Rich and Follis, Bull. Johns Hopkins Hosp., 62, 77 (1938). Greev, Campbell and Culley, Proc. Soc. Exp. Biol. and Med., 39, 22 (1938). Buttle and Parish, Brit. Med.J., 2, 776 (1938).

${ }^{2}$ Feldman and Hinshaw, Proc. Staff Meet., Mayo Clin., 14, 174 (1939). 'Birkhaug, Brit. Med. J., 2, 54 (1939).

- Ballon, Guernon and Simon, Amer. Rev. Tuberculosis, 4:, 217 (1942).

' Hinshaw and Feldman, $J$. Amer. Med. Assoc., 117, 1066 (1941). Feldman, Hinshaw and Moses, Amer. Rev. Tuberculosis, 45, 303 (1942).

- Grossley, Northey and Hultquist, $J$. Amer. Chem. Soc., 61, 2950 (1939). Cf. also Bergmann and Haskelberg, J. Amer. Chem. Soc., 63, 2243 (1941).

'Climenko, Prec. Soc. Exp. Biol. and Med., 43, 624 (1940). Steinbach and Duca, ibid., 44, 133 (1940). Muschenheim, Forkner and Duerschner, ibid., 45, 556 (1940).

- Arnold, Helmert, Möbus, Prigge, Rauen and Wagner-Jauregg, Ber. d. deutsch. Chem. Ges., 75, 369 (1942).

- Jensen and Kjaer, Dansk. Tidskr. Farmaci, 16, 110 (1942).

19 Arnold, Ber. d. deutsch. Chem. Ges., 75, 87 (1942).

${ }^{11}$ Anderson and Newman, J. Biol. Chem., 108, 197 (1933). Almquist, Pentler and Mecchi, Proc. Soc. Exp. Biol. and Med., 38, 336 (1938).

${ }^{12}$ Woolley and McCarter, Proc. Soc. Exp. Biol. and Med., 45, 357 (1940).

${ }^{13}$ Cf. Fieser and co-workers, J. Biol. Chem., 137, 859 (1941). Sjögren and Sundberg, Acta Physiol. Scand., 2, 227 (1941).

\section{The Golden Hamster as a Test Animal for Tubercular Infection}

THE bacteriological diagnosis of specimens for presence of Koch's bacilli and testing of compounds for their antitubercular properties are mainly restricted to guinea pigs and rabbits; mice are naturally resistant to tuberculous infections, and lesions produced after injecting massive doses of tubercle cultures differ from those found in susceptible animals. We have now been able to confirm that the Syrian or golden hamster (Cricetus (Mesocricetus) auratus Waterhouse), after intramuscular or intra- peritoneal infections with a human or a bovine strain, develops anatomical lesions similar to those seen in guinea pigs.

The lesions produced with doses as small as 0.001 mgm. of a virulent human strain have, after a period of 16-20 days, already developed sufficiently to give post-mortem findings (enlargement of lymphatic nodules close to the place of injection, enlargement of aortic and mesenteric glands, enlargement of spleen, miliary eruptions in liver, kidney and lungs) visible to the naked eye.

Hamsters thus offer considerable advantages in this type of experimental work. Besides being susceptible to infection with Koch's bacilli, they are small animals and are thus more economical of food and space than are rabbits or guinea pigs. Moreover, having an exceptionally short period of gestation and an average litter size similar to that of the rat (7-8 animals), a colony of adequate size can be built up more rapidly than can an equivalent colony of rabbits or guinea pigs ; finally, the hamsters available in Great Britain, being highly inbred stock, have a genetic uniformity that makes them specially suitable for biological tests.

$$
\begin{gathered}
\text { Therapeutic Research Corporation } \\
\text { of Great Britain, Ltd., } \\
183 \text { Euston Road, } \\
\text { London, N.W.1. } \\
\text { Sept. 25. }
\end{gathered}
$$

\section{J. UNGAR.}

\section{Viscosity and Chemical Constitution}

Surface tension, $\sigma$, and viscosity, $\eta$, are regarded as manifestations of van der Waals' intermolecular forces of attraction. If, therefore, rise in temperature merely separates the molecules of a liquid, $\sigma$ should be proportional to $\eta^{\frac{1}{2}}$, since $\sigma$ is expressed in force units per cm. and $\eta$ per cm. ${ }^{2}$. This is approximately true for unassociated liquids over a considerable temperature range from the boiling point downwards.

Replacing of by $\eta^{\frac{1}{8}}$ in Sugden's parachor, gives $M_{\eta} \frac{1}{8} D=$ constant $=R$ (say), wher $\Theta M$ is the molecular weight and $D$ the density. $R$ is of the same order of constancy as the parachor over the above range of temperature and enables us to compare molar volumes of different substances at constant $\eta$. $R$ is additive and a constant fraction of the critical volume. Analogous isomerides yield identical values. $R$ thus promises to be a useful instrument for studying the constitution of liquids. By analogy with parachor, the name rheochor (Gk. rheos, stream) is suggested. At a later date it is hoped to publish elsewhere a detailed application of this expression.
Technical College, Birmingham. Sept. 25.

\section{A Rheological Chart}

Followne the classification of rheological properties discussed in Nature of June 20, 1942, p. 702, the following chart is proposed. The ehart, which is largely self-explanatory, is based on the scheme of classification proposed by Dr. Treloar and developed by Mr. D. C. Broome and the British Rheologists' Club. 